\title{
Adaptive Learning and Monetary Policy Design*
}

\author{
George W. Evans \\ University of Oregon \\ Seppo Honkapohja \\ University of Helsinki and Bank of Finland
}

November 8, 2002

\begin{abstract}
We review the recent work on interest rate setting, which emphasizes the desirability of designing policy to ensure stability under private agent learning. Appropriately designed expectations based rules can yield optimal rational expectations equilibria that are both determinate and stable under learning. Some simple instrument rules and approximate targeting rules also have these desirable properties. We take up various complications in implementing optimal policy, including the observability of key variables and the required knowledge of structural parameters. An additional issue that we take up concerns the implications of expectation shocks not arising from transitional learning effects.
\end{abstract}

Key words: Commitment, interest rate setting, adaptive learning, stability, determinacy, expectations shocks.

JEL classification: E52, E31, D84.

*Presented at the 2002 Journal of Money, Credit and Banking Conference on Recent Developments in Monetary Macroeconomics. We thank John Duffy and Tom Sargent for their comments. Financial support from US National Science Foundation, the Academy of Finland, Yrjö Jahnsson Foundation, Bank of Finland and Nokia Group is gratefully acknowledged. 


\section{Introduction}

The conduct of monetary policy in terms of interest rate or other rules has been extensively studied in recent research, for surveys see e.g. (Clarida, Gali, and Gertler 1999), (Woodford 1999b) and (McCallum 1999). This literature gives a central role for forecasts of future inflation and output. Empirical evidence on Germany, Japan and the US since 1979 provided by (Clarida, Gali, and Gertler 1998) suggests that central banks are forward looking in practice. Bank of England Inflation Reports, see (Bank of England 2002), discuss private sector forecasts while the June and December Issues of the Monthly Bulletin of the European Central Bank, see (European Central Bank 2002), present both internal macroeconomic projections and forecasts by other institutions. However, the precise role of these forecasts in the decision making of these central banks is not revealed.

The question of whether monetary policy should be forward looking has been subject to discussion and debate. ${ }^{1}$ Some formulations of optimal monetary policy specify the interest rate reaction function solely in terms of fundamentals. Instrument rules such as variants of the Taylor rule are also widely considered, and discussions focus in part on whether or not the shortterm nominal interest rate should react to forecasts of inflation and/or the output gap. Theoretical studies have shown that, because the private economy is in any case forward looking, there are two potential difficulties that monetary policy design must confront.

First, the proposed interest rate rules may not perform well when the expectations of the agents are out of equilibrium, e.g. as a result of structural shifts. The consequences of temporary errors in forecasting, and the resulting correction mechanisms, have been studied in recent research using the adaptive learning approach. ${ }^{2}$ For monetary policy (Evans and Honkapohja 2002a) and (Evans and Honkapohja 2002b) show that certain standard forms of optimal interest rate setting by the Central Bank can lead to instability as

\footnotetext{
${ }^{1}$ General discussions sometimes pose the question of whether central banks should focus attention on economic fundamentals or "follow the markets", which "sometimes stray far from fundamentals", see e.g. pp. 60-61 of (Blinder 1998). (Hall 1984), p.146, suggested some time ago that the "Fed's internal procedure" should place some weight on "reliable outside forecasts."

${ }^{2}$ (Evans and Honkapohja 2001) is an extensive treatise on the analysis of adaptive learning and its implications in macroeconomics. (Evans and Honkapohja 1999), (Evans and Honkapohja 1995), (Marimon 1997), (Sargent 1993) and (Sargent 1999) provide surveys of the field.
} 
economic agents unsuccessfully try to correct their forecast functions over time, with the result that the economy may not converge to the desired rational expectations equilibrium (REE). They also propose a new method of implementing optimal policy that always leads to stability under learning. (Bullard and Mitra 2002) consider the stability of equilibria when monetary policy is conducted using variants of the Taylor interest rate rule. Bullard and Mitra argue that monetary policy making should take into account the learnability constraints, which imply constraints on the parameters of policy behavior. $^{3}$

Second, monetary policy rules, including some formulations for optimal setting of the instrument and some Taylor rules based on forecasts of inflation and/or output gap, can lead to indeterminacy of equilibria, as discussed further below. Under indeterminacy there are multiple, even continua of REE and the economy need not settle in the desired REE. The possible rest points can be studied using stability under learning as a selection criterion, see e.g. (Honkapohja and Mitra 2001a) and (Carlstrom and Fuerst 2001). We note that indeterminacy is not a critical problem if the fundamental REE is the only stable equilibrium under learning. Moreover, indeterminacy need not arise if the forward-looking interest rate rule is carefully designed, see (Bullard and Mitra 2002), (Evans and Honkapohja 2002a) and (Evans and Honkapohja 2002b).

In this paper we review recent results on the performance of interest rate rules using stability under learning as the key criterion (though we also provide some discussion of determinacy of equilibria). We consider both target rules that are optimal either under commitment or discretion and also instrument rules that do not explicitly aim for optimality. The latter include extensions or variants of the rule proposed by (Taylor 1993) as well as approximate targeting rules suggested recently by (McCallum and Nelson 2000).

After reviewing the theoretical results we take up a number of practical concerns that can arise when forecast based rules for interest rate setting are employed. The first issue is observability of relevant variables. Issues of non-observability can arise in connection with private forecasts that are

\footnotetext{
${ }^{3}$ Other papers on monetary policy using the learning approach include (Bullard and Mitra 2001), (Mitra 2001), (Honkapohja and Mitra 2001a), (Honkapohja and Mitra 2002), (Carlstrom and Fuerst 2001), (Orphanides and Williams 2002), (Ferrero 2002), (Preston 2002) and (Evans and Ramey 2001). An important predecessor to this work is (Howitt 1992), though he did not use the New Keynesian framework.
} 
needed for the desired implementation of optimal policy suggested by (Evans and Honkapohja 2002a) and (Evans and Honkapohja 2002b), as well as with current data as noted in (Bullard and Mitra 2002) and (McCallum and Nelson 2000). Second, we introduce expectation shocks and study whether they affect the conclusions derived when these shocks are absent. The third concern is knowledge of the structure of the economy that is required for implementation of optimal interest rate policies. We extend the analysis of optimal commitment policy under private agent learning to a situation in which the central bank estimates the structural parameters of the economy and uses these estimates in their rule for setting interest rates.

\section{The Model}

We use a linearized model that is standard in the literature, see (Clarida, Gali, and Gertler 1999) for the particular formulation used here. The original nonlinear framework is based on a representative consumer, and a continuum of firms producing differentiated goods under monopolistic competition. Firms are subject to constraints on the frequency of price changes, as originally suggested by (Calvo 1983). ${ }^{4}$

The behavior of the private sector is summarized by the two equations

$$
x_{t}=-\varphi\left(i_{t}-E_{t}^{*} \pi_{t+1}\right)+E_{t}^{*} x_{t+1}+g_{t},
$$

which is the "IS" curve derived from the Euler equation for consumer optimization, and

$$
\pi_{t}=\lambda x_{t}+\beta E_{t}^{*} \pi_{t+1}+u_{t}
$$

which is the price setting rule for the monopolistically competitive firms.

Here $x_{t}$ and $\pi_{t}$ denote the output gap and inflation rate for period $t$, respectively. $i_{t}$ is the nominal interest rate, expressed as the deviation from the steady state real interest rate. The determination of $i_{t}$ will be discussed below. $E_{t}^{*} x_{t+1}$ and $E_{t}^{*} \pi_{t+1}$ denote private sector expectations of the output gap and inflation next period. Since our focus is on learning behavior, these expectations need not be rational $\left(E_{t}\right.$ without $*$ denotes rational expectations). The parameters $\varphi$ and $\lambda$ are positive and $\beta$ is the discount factor with $0<\beta<1$.

\footnotetext{
${ }^{4}$ See e.g. (Woodford 1996) for the nonlinear model and its linearization.
} 
For brevity we do not discuss details of the derivation of equations (1) and (2). It should be pointed out that the derivation is based on individual Euler equations under (identical) subjective expectations, together with aggregation and definitions of the variables, see (Evans and Honkapohja 2002b) for a further discussion. The Euler equations for the current period give the decisions as functions of the expected state next period. Rules for forecasting the next period's values of the state variables are the other ingredient in the description of individual behavior. Given forecasts, agents make decisions according to the Euler equations. ${ }^{5}$

The shocks $g_{t}$ and $u_{t}$ are assumed to be observable and follow

$$
\left(\begin{array}{l}
g_{t} \\
u_{t}
\end{array}\right)=F\left(\begin{array}{l}
g_{t-1} \\
u_{t-1}
\end{array}\right)+\left(\begin{array}{c}
\tilde{g}_{t} \\
\tilde{u}_{t}
\end{array}\right)
$$

where

$$
F=\left(\begin{array}{cc}
\mu & 0 \\
0 & \rho
\end{array}\right)
$$

$0<|\mu|<1,0<|\rho|<1$ and $\tilde{g}_{t} \sim \operatorname{iid}\left(0, \sigma_{g}^{2}\right), \tilde{u}_{t} \sim i i d\left(0, \sigma_{u}^{2}\right)$ are independent white noise. $g_{t}$ represents shocks to government purchases and/or potential output. $u_{t}$ represents any cost push shocks to marginal costs other than those entering through $x_{t}$. For simplicity, we assume throughout the paper that $\mu$ and $\rho$ are known (if not, they could be estimated).

The recent literature on monetary policy has focused on interest rate setting by the Central Bank. ${ }^{6}$ One approach examines "instrument rules" that specify $i_{t}$ in terms of key macroeconomic variables without explicit consideration of policy optimization. A prominent example of this type is the standard (Taylor 1993) rule, i.e.,

$$
i_{t}=\pi_{t}+0.5\left(\pi_{t}-\bar{\pi}\right)+0.5 x_{t},
$$

\footnotetext{
${ }^{5}$ This kind of behavior is boundedly rational but in our view reasonable since agents attempt to meet the margin of optimality between the current and the next period. Other models of bounded rationality are possible. Recently, (Preston 2002) has proposed a formulation in which long horizons matter in individual behavior. For further discussion see (Honkapohja, Mitra, and Evans 2002).

${ }^{6}$ We follow the common practice of leaving hidden the government budget constraint and the equation for the evolution of government debt. This is acceptable provided fiscal policy appropriately accommodates the consequences of monetary policy for the government budget constraint. The interaction of monetary and fiscal policy can be important for the stability of equilibria under learning, see (Evans and Honkapohja 2002c) and (McCallum 2002).
} 
where $\bar{\pi}$ is the target levels of inflation and the target level of the output gap is zero. (Recall that $i_{t}$ is specified net of the real interest rate, which in the standard Taylor rule is usually set at 2\%). More generally Taylor-type rules are of the form $i_{t}=\chi_{0}+\chi_{\pi} \pi_{t}+\chi_{x} x_{t}$. For convenience (and without loss of generality) we will take the inflation target to be $\bar{\pi}=0$ so that this class of rules takes the form

$$
i_{t}=\chi_{\pi} \pi_{t}+\chi_{x} x_{t} \text { where } \chi_{\pi}, \chi_{x}>0 \text {. }
$$

Variations of the Taylor rule replace $\pi_{t}$ and $x_{t}$ by lagged values or by forecasts of current or future values, e.g. in the former case by

$$
i_{t}=\chi_{\pi} \pi_{t-1}+\chi_{x} x_{t-1} \text { where } \chi_{\pi}, \chi_{x}>0
$$

Alternatively, interest rate policy can be derived explicitly to maximize a policy objective function. This is frequently taken to be of the quadratic loss form, i.e.

$$
E_{t} \sum_{s=0}^{\infty} \beta^{s}\left[\left(\pi_{t+s}-\bar{\pi}\right)^{2}+\alpha x_{t+s}^{2}\right],
$$

where $\bar{\pi}$ is the inflation gap. This type of optimal policy is often called "flexible inflation targeting" in the current literature, see e.g. (Svensson 1999) and (Svensson 2001). $\alpha$ is the relative weight on the output target and strict inflation targeting would be the case $\alpha=0$. The policy maker is assumed to have the same discount factor $\beta$ as the private sector.

The literature on optimal policy distinguishes between optimal discretionary policy, in which the policy maker is unable to commit to policies for future periods, and optimal policy in which such commitment is possible. Without commitment policy is reoptimized each period and reduces to a sequence of static problems in which the Central Bank aims to minimize $\left(\pi_{t}-\bar{\pi}\right)^{2}+\alpha x_{t}^{2}$ subject to (2). This leads to the first-order condition $\lambda\left(\pi_{t}-\bar{\pi}\right)+\alpha x_{t}=0$. Again, for convenience and without loss of generality we set $\bar{\pi}=0$ so that the optimality condition is

$$
\lambda \pi_{t}+\alpha x_{t}=0
$$

Under commitment the policy maker can do better because of the effect on private expectations. Solving the problem of minimizing (6) subject to (2) holding in every period, and assuming RE, leads to a series of first order 
conditions for the optimal dynamic policy. This policy exhibits time inconsistency, in the sense that policy makers would have an incentive to deviate from the policy in the future, but performs better than discretionary policy. Assuming that the policy has been initiated at some point in the past, and again setting $\bar{\pi}=0$, the first-order condition specifies

$$
\lambda \pi_{t}+\alpha\left(x_{t}-x_{t-1}\right)=0
$$

in every period. ${ }^{7}$

Neither condition (7) for optimal discretionary policy nor condition (8) for optimal policy with commitment is a complete specification of monetary policy, since one must still look for an $i_{t}$ rule (also called a "reaction function") that implements the policy. It turns out that a number of interest rate rules are consistent with the model (1)-(2), the optimality condition (7) or (8), and rational expectations. However, and this point is fundamental, some of the ways of implementing "optimal" monetary policy lead the economy vulnerable to either indeterminacy or instability under learning or both, while other implementations are robust to these difficulties.

The implementations of optimal policy that we will consider can be divided into "fundamentals based" and "expectations based" rules. The fundamentals based rule depends only on the observable exogenous shocks $g_{t}$ and $u_{t}$ in the case of discretionary policy, i.e.

$$
i_{t}=\psi_{g} g_{t}+\psi_{u} u_{t}
$$

Under policy with commitment the fundamentals based rule must also depend on $x_{t-1}$ so that

$$
i_{t}=\psi_{x} x_{t-1}+\psi_{g} g_{t}+\psi_{u} u_{t}
$$

where the optimal coefficients are determined by the structural parameters and the policy objective function. The coefficients $\psi_{i}$ are chosen so that the effects of aggregate demand shocks $g_{t}$ are neutralized and so that for inflation shocks $u_{t}$ the optimal balance is struck between output and inflation effects. In (10) the dependence of $i_{t}$ on $x_{t-1}$ is optimally chosen to take advantage of the effects on expectations of commitment to a rule. Calculation of the coefficients $\psi_{i}$ requires first calculating the optimal REE and then inserting

\footnotetext{
${ }^{7}$ Treating the policy as having been initiated in the past correspond to the "timeless perspective" described by (Woodford 1999a) and (Woodford 1999b).
} 
the solution into the IS curve (1) to obtain the $i_{t}$ rule of the desired form. These steps are summarized in Appendix 1.

Expectations based optimal rules are advocated in (Evans and Honkapohja 2002a) and (Evans and Honkapohja 2002b). They argue that fundamentals based optimal rules will often be unstable under learning, as discussed below. However, if private expectations are observable then they can be incorporated into the interest rate policy rule. If this is done appropriately the REE will be stable under learning and thus optimal policy can be successfully implemented. Optimal expectations based rules take the form

$$
i_{t}=\delta_{\pi} E_{t}^{*} \pi_{t+1}+\delta_{x} E_{t}^{*} x_{t+1}+\delta_{g} g_{t}+\delta_{u} u_{t},
$$

under discretion or

$$
i_{t}=\delta_{L} x_{t-1}+\delta_{\pi} E_{t}^{*} \pi_{t+1}+\delta_{x} E_{t}^{*} x_{t+1}+\delta_{g} g_{t}+\delta_{u} u_{t}
$$

under commitment. The specific coefficients will be derived below. The essence of these rules is that they do not assume rational expectations on the part of private agents, but are designed to feed back on private expectations in such a way that they generate convergence to the optimal REE under learning. (If expectations are rational, these rules deliver the optimal REE.)

Finally, we will also examine the types of rule introduced by (McCallum and Nelson 2000), which aim to approximate optimal policy using an interest rate rule based on $x_{t}$ and $\pi_{t}$. (McCallum and Nelson 2000) consider instrument rules of the form

$$
i_{t}=\pi_{t}+\theta\left[\pi_{t}+(\alpha / \lambda)\left(x_{t}-x_{t-1}\right)\right]
$$

where $\theta>0$. From now on we will call this rule simply the approximate targeting rule. For reasons discussed below, they also examine a forward looking version of this rule.

Given an interest rate rule we can obtain the reduced from of the model and study its properties under rational expectations. The particular properties in which we are interested are determinacy (uniqueness) of the RE solution and the stability under learning of the REE of interest. We now turn to these issues. 


\section{Determinacy and Stability under Learning}

Consider the system given by (1), (2), (3) and one of the $i_{t}$ policy rules (4), (5), (9), (10), (11), (12) or (13). Defining

$$
y_{t}=\left(\begin{array}{c}
x_{t} \\
\pi_{t}
\end{array}\right) \text { and } v_{t}=\left(\begin{array}{c}
g_{t} \\
u_{t}
\end{array}\right)
$$

the reduced form can be written as

$$
y_{t}=M E_{t}^{*} y_{t+1}+N y_{t-1}+P v_{t}
$$

for appropriate matrices $M, N$ and $P$. In the case of rules (4), (9), and (11) we have $N=0$ and thus the simpler system

$$
y_{t}=M E_{t}^{*} y_{t+1}+P v_{t}
$$

The first issue of concern is whether under rational expectations the system possesses a unique stationary REE, in which case the model is said to be "determinate." If instead the model is "indeterminate," so that multiple stationary solutions exist, these will include undesirable "sunspot solutions", i.e. REE depending on extraneous random variables that influence the economy solely through the expectations of the agents. The possibility of interest rate rules leading to indeterminacy was demonstrated in (Bernanke and Woodford 1997), (Woodford 1999b) and (Svensson and Woodford 1999) and this issue was further investigated in (Bullard and Mitra 2002), (Evans and Honkapohja 2002a) and (Evans and Honkapohja 2002b).

The second issue concerns stability under adaptive learning. If private agents follow an adaptive learning rule, such as least squares, will the RE solution of interest be stable, i.e. reached asymptotically by the learning process? If not, the REE is unlikely to be reached because the specified policy is potentially destabilizing. This is the focus of the papers by (Bullard and Mitra 2002), (Bullard and Mitra 2001), (Evans and Honkapohja 2002a), (Evans and Honkapohja 2002b) and others.

\subsection{General Methodology}

Consider first the reduced form (15) under RE. It is well known that the condition for determinacy is that both eigenvalues of the $2 \times 2$ matrix $M$ 
lie outside the unit circle. In the determinate case the unique stationary solution will be of the "minimal state variable" (or MSV) form

$$
y_{t}=\bar{c} v_{t}
$$

where $\bar{c}$ is a $2 \times 2$ matrix that is easily computed. If instead one or both roots lie inside the unit circle then the model is indeterminate. There will still be a solution of the MSV form, but there will also be other stationary solutions.

Next consider the system under learning. Suppose that agents believe that the solution is of the form

$$
y_{t}=a+c v_{t}
$$

but that the $2 \times 1$ vector $a$ and the $2 \times 2$ matrix $c$ are not known but instead are estimated by the private agents. (16) is called the "Perceived Law of Motion" or PLM of the agents. Note that we now include an intercept vector because, although for theoretical simplicity we have translated all variables to have zero means, in practice agents will need to estimate intercept as well as slope parameters.

With this PLM and parameter estimates $(a, c)$ agents would form expectations as

$$
E_{t}^{*} y_{t+1}=a+c F v_{t}
$$

where either $F$ is known or is also estimated. Inserting these expectations into (15) and solving for $y_{t}$ we get the implied "Actual Law of Motion" or ALM, i.e. the law that $y_{t}$ would follow for a fixed PLM $(a, c)$. This is given by

$$
y_{t}=M a+(P+M c F) v_{t} .
$$

We have thus obtained an associated mapping from PLM to ALM given by

$$
T(a, c)=(M a, P+M c F),
$$

and $(0, \bar{c})$ is a fixed point of this map.

Under real time learning private agents have estimates $\left(a_{t}, c_{t}\right)$ at time $t$, which they use to form expectations $E_{t}^{*} y_{t+1}=a_{t}+c_{t} F v_{t}$ (assuming for convenience that $F$ is known), and $y_{t}$ is generated according to (15). Then at the beginning of $t+1$ agents use the last data point to update their parameter estimates to $\left(a_{t+1}, c_{t+1}\right)$, e.g. using least squares, and the process continues. 
(Section 6 gives details on the form of the least squares algorithms.) The question is whether over time $\left(a_{t}, c_{t}\right) \rightarrow(0, \bar{c})$.

It turns out that the answer to this question is given by the E-stability principle, which advises us to look at the differential equation

$$
\frac{d}{d \tau}(a, c)=T(a, c)-(a, c),
$$

where $\tau$ denotes notional time. If the $\operatorname{REE}(0, \bar{c})$ is locally asymptotically stable under this differential equation then the REE is stable under real time learning. Conditions for local stability of this differential equation are known as expectational stability or "E-stability" conditions. We will also refer to these stability conditions as the "conditions for stability under adaptive learning" or just the "conditions for stability under learning". ${ }^{8}$

For the reduced form (15) it can be shown that the E-stability conditions are that (i) the eigenvalues of $M$ have real parts less than one and (ii) all products of eigenvalues of $M$ times eigenvalues of $F$ have real parts less than one. It follows that for this reduced form the conditions for stability under adaptive learning are implied by determinacy but not vice versa. This is not, however, a general result. For some reduced forms E-stability is a stricter requirement than determinacy and in other reduced forms neither condition implies the other. ${ }^{9}$

Consider next the reduced form (14). Standard techniques are available to determine whether the model is determinate. The procedure is to rewrite the model in first-order form and compare the number of non-predetermined variables with the number of roots of the forward looking matrix that lie inside the unit circle. In the determinate case the unique stationary solution takes the MSV form

$$
y_{t}=a+b y_{t-1}+c v_{t},
$$

for appropriate values $(a, b, c)=(0, \bar{b}, \bar{c})$. (In the indeterminate case there are multiple solutions of this form, as well as non-MSV REE).

\footnotetext{
${ }^{8}$ (Evans and Honkapohja 2001) describes the concepts and methods for the study of adaptive learning. The eductive approach to learning, in which agents use mental reasoning, is also sometimes used, see (Guesnerie 2002) for a review. The connections between stability under adaptive and eductive learning are discussed in (Evans 2001).

${ }^{9}$ If the model is indeterminate, so that sunspot solutions exist, then one can also ask whether the sunspot solutions are stable under learning. For a general discussion see (Evans and Honkapohja 2001) and for an analysis of the model at hand see (Honkapohja and Mitra 2001a) and (Carlstrom and Fuerst 2001).
} 
To examine stability under learning we treat (17) as the PLM of the agents. Under real time learning agents estimate the coefficients $a, b, c$ of (17). This is a vector autoregression (VAR) with exogenous variables $v_{t}$. The estimates $\left(a_{t}, b_{t}, c_{t}\right)$ are updated at each point in time by recursive least squares. Once again it can be shown that the E-stability principle gives the conditions for local convergence of real time learning.

For E-stability we compute the mapping from the PLM to the ALM as follows. The expectations corresponding to (17) are given by

$$
E_{t}^{*} y_{t+1}=a+b\left(a+b y_{t-1}+c v_{t}\right)+c F v_{t},
$$

where we are treating the information set available to the agents, when forming expectations, as including $v_{t}$ and $y_{t-1}$ but not $y_{t}$. (Alternative information assumptions are straightforward to consider). This leads to the mapping from PLM to ALM given by

$$
T(a, b, c)=\left(M(I+b) a, M b^{2}+N, M(b c+c F)+P\right),
$$

E-stability is again determined by the differential equation

$$
\frac{d}{d \tau}(a, b, c)=T(a, b, c)-(a, b, c)
$$

and the E-stability conditions govern stability under least squares learning. For further details see Chapter 10 of (Evans and Honkapohja 2001) and (Bullard and Mitra 2002), (Bullard and Mitra 2001), (Evans and Honkapohja 2002a) and (Evans and Honkapohja 2002b).

\subsection{Results for Monetary Policy}

We now describe the determinacy and stability results for the interest rate rules described in Section 2. (Bullard and Mitra 2002) consider Taylor type rules and find that the results are sensitive to whether the $i_{t}$ rule conditions on current, lagged or expected future output and inflation. In addition to assuming that $\chi_{\pi}, \chi_{x} \geq 0$, they assume that the serial correlation parameters in $F$ are nonnegative. For the rule (4) the results are particularly straightforward and natural. (Bullard and Mitra 2002) show that the model is determinate and stable under learning if and only if ${ }^{10}$ (using our notation)

$$
\lambda\left(\chi_{\pi}-1\right)+(1-\beta) \chi_{x}>0 .
$$

\footnotetext{
${ }^{10}$ Throughout we will assume that we are not exactly on the border of the regions of determinacy or stability.
} 
In particular, if policy obeys the "Taylor principle" that $\chi_{\pi}>1$, so that nominal interest rates respond at least one for one with inflation, then determinacy and stability are guaranteed.

If lagged or forward looking Taylor rules are used the situation is more complicated. Full analytical results are not available, but (Bullard and Mitra 2002) investigate the issues numerically using a calibrated version of the model. Under (5) they find that for $\chi_{\pi}>1$ and $\chi_{x}>0$ sufficiently small the policy leads to an REE that is determinate and stable under learning. For $\chi_{\pi}>1$ but $\chi_{x}$ too large the system is explosive. For $\chi_{\pi}<1$ the possibilities include regions of $\chi_{\pi}, \chi_{x}$ space that are determinate but unstable.

(Bullard and Mitra 2002) also look at forward looking versions of the Taylor rule, taking the form

$$
i_{t}=\chi_{\pi} E_{t}^{*} \pi_{t+1}+\chi_{x} E_{t}^{*} x_{t+1} \text { where } \chi_{\pi}, \chi_{x}>0,
$$

where we can interpret $E_{t}^{*} \pi_{t+1}$ and $E_{t}^{*} x_{t+1}$ as identical one step ahead forecasts, based on least squares updating, used by both private agents and policy makers. Again we find that for $\chi_{\pi}>1$ and $\chi_{x}>0$ sufficiently small the policy leads to an REE that is determinate and stable under learning. Now for $\chi_{\pi}>1$ and $\chi_{x}$ large the system is indeterminate, yet the MSV solution is stable under learning (while for $\chi_{\pi}<1$ there are regions in which the system is indeterminate but the MSV solution is not stable). ${ }^{11}$

The (Bullard and Mitra 2002) results emphasize the importance of the Taylor principle in obtaining stable and determinate interest rate rules. At the same time their results show that stability under learning must not be taken for granted, even when the system is determinate so that a unique stationary solution exists. The parameters of the policy rule $\chi_{\pi}, \chi_{x}$ must be appropriately selected by the policy maker when an instrument rule describes policy. Stability under learning provides a constraint for this choice.

As outlined above, in (Evans and Honkapohja 2002a) and (Evans and Honkapohja 2002b) we focus on optimal monetary policy and obtain striking negative results for fundamentals based policy rules (9), (10). Under optimal discretionary policy, with $i_{t}$ rule $(9)$, the system is invariably unstable under private agent learning (the system is also invariably indeterminate in this case). The basic intuition for this result is that, say, upward mistakes in

\footnotetext{
${ }^{11}$ For interest rate rule (21) there exist E-stable sunspot equilibria if $\lambda\left(\chi_{\pi}-1\right)+(1-$ $\beta) \chi_{x}>0$ and $\lambda\left(\chi_{\pi}-1\right)+(1-\beta) \chi_{x}>2 \varphi^{-1}(1+\beta)$, see (Honkapohja and Mitra 2001a). Thus policy under (21) should not be "too aggressive".
} 
$E_{t}^{*} \pi_{t+1}$ lead to higher $\pi_{t}$, both directly and indirectly through lower ex ante real interest rates, which under learning sets off a cumulative movement away from REE. One might hope that the feedback from $x_{t-1}$ under (10), the fundamentals based $i_{t}$ rule with commitment, would stabilize the economy. However, we show that with this policy rule, as well, the economy is invariably unstable under learning. This is the case even though with this rule there are regions in which the optimal REE is determinate. ${ }^{12}$

The instability of the fundamentals based rules, designed after all to obtain optimal policy, is deeply worrying and serves as a strong warning to policy makers not to automatically assume that rational expectations will be attained. It is necessary to examine explicitly the robustness of contemplated policy rules to private agent learning. In (Evans and Honkapohja 2002a) and (Evans and Honkapohja 2002b) we show how the problems of instability and indeterminacy can be overcome if private agents' expectations are observable, so that interest rate rules can be in part conditioned on these expectations. We now look for appropriate rules of the form (11), (12). We focus here on the case in which policy makers can operate under commitment.

The desired rule is obtained by combining the IS curve (1), the price setting equation (2) and the first-order optimality condition (8), treating the private expectations as given. Eliminating $x_{t}$ and $\pi_{t}$ from these equations, but not imposing the rational expectations assumption, leads to an interest rate equation of the form (12) with coefficients

$$
\begin{aligned}
\delta_{L} & =\frac{-\alpha}{\varphi\left(\alpha+\lambda^{2}\right)}, \\
\delta_{\pi} & =1+\frac{\lambda \beta}{\varphi\left(\alpha+\lambda^{2}\right)}, \delta_{x}=\varphi^{-1}, \\
\delta_{g} & =\varphi^{-1}, \delta_{u}=\frac{\lambda}{\varphi\left(\alpha+\lambda^{2}\right)} .
\end{aligned}
$$

Under optimal discretionary policy (7) is used instead and the coefficients are identical except that $\delta_{L}=0$.

Under this expectations based optimal rule we obtain equally striking positive results. For all possible structural parameter values the system is

\footnotetext{
${ }^{12}$ In the case of policy with commitment the learning stability results are sensitive to the detailed information assumptions. With PLM (17) if agents can make forecasts conditional also on $y_{t}$ then under the fundamentals based rule there are both regions of stability and instability, depending on the structural parameters.
} 
determinate and the optimal REE is stable under private agent learning. The key to the stability results is the feedback from expectations to interest rates, so that deviations from rational expectations are offset by policy and in such a way that under learning private agents are guided over time to form expectations consistent with the optimal REE. Note that our expectations based rule obeys a form of the Taylor principle since $\delta_{\pi}>1$. Note also that our optimal policy rule conditions on both private expectations and observable exogenous shocks, as well as lagged output. ${ }^{13}$

Finally, we consider the approximate targeting rules of (McCallum and Nelson 2000). In (Evans and Honkapohja 2002b) we numerically investigate the rule (13) and find that it is also invariably determinate and stable under learning. Since it can be shown that for large $\theta>0$ the resulting REE will be close to the optimal REE, this also provides an attractive policy rule. As (McCallum and Nelson 2000) point out, a potential difficulty with this rule is that it requires contemporaneous observations of aggregate output and inflation when setting the interest rate. They therefore consider alternative versions of their approximate targeting rule and in particular recommend a forward looking version, which is discussed below.

\section{Operationality}

Many of the $i_{t}$ rules discussed above have the potential difficulty that they may not be operational, as discussed in (McCallum 1999) . For example, (McCallum and Nelson 2000) note that it may be unrealistic to assume that policy makers can condition policy on current $x_{t}$ and $\pi_{t}$. Similarly, one could question whether accurate observations on private expectations are available. We consider these points in the reverse order.

\subsection{Observability of Private Expectations}

Our recommended expectations based rule requires observations of current private expectations of future variables. Survey data on private forecasts of future inflation and various measures of future output do exist but there are

\footnotetext{
${ }^{13}$ In the context of optimal discretionary policy (Ferrero 2002) takes up the additional issue of the speed of convergence under least squares learning. There is a continuum of expectations based rules of the form (11) that are consistent with the optimal discretionary REE but these can have different speeds of convergence.
} 
concerns about the accuracy of this data. If observations of expectations are subject to a white noise measurement error then our stability and determinacy results are unaffected. Furthermore, if measurement errors are small then the policy will be close to optimal. However, if measurement errors are large then this will lead to a substantial deterioration in performance. In this case one might consider substituting a proxy for such observations. Since we are assuming that agents forecast by running VARs, the most natural proxy is for the Central Bank to estimate corresponding VARs and use these in (12). Clearly, if this precisely describes agents forecasts then it is equivalent to observing these expectations. However, we can consider less extreme cases in which agents and the Central Bank begin with different initial estimates and/or use data sets with different initial dates.

For the case of optimal discretionary policy and forward based instrument rules this issue was analyzed in (Honkapohja and Mitra 2002). We here show that using VAR proxies can also achieve convergence to the optimal REE with commitment. Before proceeding with this analysis we note that in the case in which private expectations are observed and incorporated into our expectations based rule (12), the reduced form is given by (14) with

$$
M=\left(\begin{array}{cc}
0 & -\frac{\lambda \beta}{\alpha+\lambda^{2}} \\
0 & \frac{\alpha \beta}{\alpha+\lambda^{2}}
\end{array}\right), N=\left(\begin{array}{cc}
\frac{\alpha}{\alpha+\lambda^{2}} & 0 \\
\frac{\alpha \lambda}{\alpha+\lambda^{2}} & 0
\end{array}\right) \text { and } P=\left(\begin{array}{cc}
0 & -\frac{\lambda}{\alpha+\lambda^{2}} \\
0 & \frac{\alpha}{\alpha+\lambda^{2}}
\end{array}\right)
$$

and that (Evans and Honkapohja 2002b) show that this reduced form leads to stability and determinacy.

When the private agents and the Central Bank are separately estimating and forecasting using VARs, we must distinguish between their expectations. An extended E-stability analysis can give the conditions for convergence of learning, as shown in (Honkapohja and Mitra 2001b). In the current context this is done as follows. The equations (1)-(2) depend on private forecasts $E_{t}^{P} \pi_{t+1}$ and $E_{t}^{P} x_{t+1}$ while the interest rate rule (12) depends on Central Bank forecasts $E_{t}^{C B} \pi_{t+1}$ and $E_{t}^{C B} x_{t+1}$. Combining these equations leads to 
the reduced form

$$
\begin{aligned}
\left(\begin{array}{l}
x_{t} \\
\pi_{t}
\end{array}\right)= & \left(\begin{array}{cc}
1 & \varphi \\
\lambda & \beta+\lambda \varphi
\end{array}\right)\left(\begin{array}{c}
E_{t}^{P} x_{t+1} \\
E_{t}^{P} \pi_{t+1}
\end{array}\right)+ \\
& \left(\begin{array}{cc}
-1 & -\varphi-\frac{\lambda \beta}{\alpha+\lambda^{2}} \\
-\lambda & -\lambda\left(\varphi+\frac{\lambda \beta}{\alpha+\lambda^{2}}\right.
\end{array}\right)\left(\begin{array}{c}
E_{t}^{C B} x_{t+1} \\
E_{t}^{C B} \pi_{t+1}
\end{array}\right)+ \\
& \left(\begin{array}{cc}
\frac{\alpha}{\alpha+\lambda^{2}} & 0 \\
\frac{\alpha \lambda}{\alpha+\lambda^{2}} & 0
\end{array}\right)\left(\begin{array}{c}
x_{t-1} \\
\pi_{t-1}
\end{array}\right)+\left(\begin{array}{cc}
0 & -\frac{\lambda}{\alpha+\lambda^{2}} \\
0 & 1-\frac{\lambda^{2}}{\alpha+\lambda^{2}}
\end{array}\right)\left(\begin{array}{l}
g_{t} \\
u_{t}
\end{array}\right)
\end{aligned}
$$

or in matrix form

$$
y_{t}=M_{P} E_{t}^{P} y_{t+1}+M_{C B} E_{t}^{C B} y_{t+1}+N y_{t-1}+P v_{t}
$$

where $y_{t}^{\prime}=\left(x_{t}, \pi_{t}\right)$ and $v_{t}^{\prime}=\left(g_{t}, u_{t}\right)$. The PLMs and forecasts of private agents and the Central Bank take the form

$$
\begin{aligned}
y_{t} & =a_{j}+b_{j} y_{t-1}+c_{j} v_{t}, \text { and } \\
E_{t}^{j} y_{t+1} & =\left(I+b_{j}\right) a_{j}+b_{j}^{2} y_{t-1}+\left(b_{j} c_{j}+c_{j} F\right) v_{t} \text { where } j=P, C B .
\end{aligned}
$$

It is easily verified that the implied ALM is of the form

$$
y_{t}=a^{*}+b^{*} y_{t-1}+c^{*} v_{t}
$$

with the associated map from the PLMs to the ALM

$$
\begin{aligned}
& \left.\begin{array}{c}
a_{P} \\
a_{C B}
\end{array}\right\} \longrightarrow a^{*} \equiv M_{P}\left(I+b_{P}\right) a_{P}+M_{C B}\left(I+b_{C B}\right) a_{C B} \\
& \left.\begin{array}{c}
b_{P} \\
b_{C B}
\end{array}\right\} \longrightarrow b^{*} \equiv M_{P} b_{P}^{2}+M_{C B} b_{C B}^{2}+N \\
& \left.\begin{array}{c}
c_{P} \\
c_{C B}
\end{array}\right\} \longrightarrow c^{*} \equiv M_{P}\left(b_{P} c_{P}+c_{P} F\right)+M_{C B}\left(b_{C B} c_{C B}+c_{C B} F\right)+P .
\end{aligned}
$$

Because the $P$ and $C B$ parameters are mapped into the same ALM parameters, it can be shown that the E-stability conditions are identical to those that obtain if forecasts are identical in the model, i.e. in which the coefficient matrix on the expectations $E_{t}^{*} y_{t+1}$ is $M_{P}+M_{C B}$. This is identical to the earlier reduced form under the interest rate rule (12). Hence we have stability here as well. ${ }^{14}$

\footnotetext{
${ }^{14}$ The corresponding real-time learning stability result is somewhat sensitive to the detailed assumptions, e.g. additional restrictions are required for stability if private agents estimate parameters using stochastic gradient techniques while the Central Bank uses least squares.
} 


\subsection{Non-Observability of Current Data}

As pointed out by (McCallum and Nelson 2000), a difficulty with the approximate targeting rule (13) is that it presupposes that the policy maker can observe current output gap and inflation when setting the interest rate. (McCallum and Nelson 2000) recommend use of forward looking versions of approximate targeting rules. In this case the policy maker adjusts the current interest rate in response to the discrepancy from the optimality condition (8) anticipated for the next period, i.e.

$$
i_{t}=E_{t}^{C B} \pi_{t+1}+\theta\left[E_{t}^{C B} \pi_{t+1}+(\alpha / \lambda)\left(E_{t}^{C B} x_{t+1}-E_{t}^{C B} x_{t}\right)\right] .
$$

This requires specification of $E_{t}^{C B}($.$) and we consider the case where both$ the Central Bank and private agents use forecasts based on identical estimated VARs, i.e. $E_{t}^{C B}()=.E_{t}^{P}()=.E_{t}^{*}($.$) . The reduced form is then$

$$
\begin{aligned}
\left(\begin{array}{l}
x_{t} \\
\pi_{t}
\end{array}\right)= & \left(\begin{array}{cc}
-\alpha \varphi \theta \lambda^{-1} & -\varphi \theta \\
-\alpha \varphi \theta & \beta-\varphi \theta \lambda
\end{array}\right)\left(\begin{array}{c}
E_{t}^{*} x_{t+1} \\
E_{t}^{*} \pi_{t+1}
\end{array}\right)+ \\
& \left(\begin{array}{cc}
\alpha \varphi \theta \lambda^{-1} & 0 \\
\alpha \varphi \theta & 0
\end{array}\right)\left(\begin{array}{l}
E_{t}^{*} x_{t} \\
E_{t}^{*} \pi_{t}
\end{array}\right)+\left(\begin{array}{cc}
1 & 0 \\
\lambda & 1
\end{array}\right)\left(\begin{array}{c}
g_{t} \\
u_{t}
\end{array}\right) .
\end{aligned}
$$

It turns out that determinacy and stability under learning are no longer guaranteed if the rule (24) is employed. Numerical results indicate that sufficiently large values of the policy parameter $\theta$ induce both instability under learning and indeterminacy. We focus here on the upper bound on $\theta$ required to avoid instability and compare the performance of (24) in terms of welfare loss against the welfare loss under optimal policy.

We consider the performance of the rule (24) for different numerical calibrations of the model,

Calibration W: $\quad \beta=0.99, \varphi=(0.157)^{-1}$ and $\lambda=0.024$;

Calibration CGG: $\quad \beta=0.99, \varphi=1$ and $\lambda=0.3$;

Calibration MN: $\quad \beta=0.99, \varphi=0.164$ and $\lambda=0.3$;

due to (Woodford 1999b), (Clarida, Gali, and Gertler 2000) and (McCallum and Nelson 1999), respectively. We also set $\alpha=0.3, \rho=0.4, \mu=0.4$, $\sigma_{g}=1$ and $\sigma_{u}=0.5$. Here $x_{t}$ and $\pi_{t}$ are expressed in percentage units. The values for $\sigma_{g}$ and $\mu$ are broadly consistent with those obtained in (McCallum and Nelson 1999). The value for $\sigma_{u}$ is close to that used by (McCallum and 
Nelson 2000). The latter paper uses a wide range of values for $\rho$ and our choice is in the middle of this range. Seriously calibrating these parameters to the data would require their values to be contingent on both $\varphi$ and $\lambda$ as well the policy rule. Because we want to compare the performance of different policy rules for given structural parameters, we must in any case fix the underlying structure of the model and therefore we simply adopt the above values as a benchmark for numerical computations.

For the different calibrations the value of the welfare loss from the rule (24), with $\theta$ set optimally under the E-stability constraint ${ }^{15}$, and for the optimal REE are as follows:

\begin{tabular}{|l||l|l|}
\hline Calibration & $W_{A T}$ & $W_{E B}$ \\
\hline \hline $\mathbf{W}$ & 7.190 & 0.755 \\
\hline $\mathbf{C G G}$ & 0.331 & 0.296 \\
\hline $\mathbf{M N}$ & 0.332 & 0.296 \\
\hline
\end{tabular}

where "AT" and "EB" refer to approximate targeting and optimal expectations based rules, respectively. (Technical details for computing the welfare loss are given in Appendix 2.) These results show that there are sometimes substantial welfare losses from using the E-stable forward looking AT rule that can be avoided if the EB rule is feasible.

\section{Expectation Shocks}

In this section we introduce another type of observability problem in private expectations. It is assumed that, though private agents are learning as before, their actual expectations are affected by additional shocks of optimism or pessimism. We initially assume that the policy maker does not see these shocks and bases its interest rate policy only on the component of expectations that comes from learning behavior. For example, the Central Bank could be running its own version of least squares learning to generate

\footnotetext{
${ }^{15}$ For the AT rule the "optimal" choice of $\theta$ is on the edge of the E-stability constraint. However, we remark that this choice is somewhat risky since a small error in the model parameter values could lead to instability. Moreover, this choice of $\theta$ could lead to slow convergence of real time learning.
} 
the required forecasts. We consider both the expectations based rule (12) and the forward looking approximate targeting rule (24). We then contrast these results with those from the EB rule when private expectations are fully observable.

We must derive the modifications to the reduced form. PLMs of private agents and the Central Bank take the familiar form

$$
y_{t}=a+b y_{t-1}+c v_{t}
$$

leading to $\tilde{E}_{t} y_{t+1}=(I+b) a+b^{2} y_{t-1}+(b c+c F) v_{t}$ and $\tilde{E}_{t} y_{t}=a+b y_{t-1}+c v_{t}$. However, the actual forecasts of private agents are now assumed to be

$$
E_{t}^{*} y_{t+1}=\tilde{E}_{t} y_{t+1}+\varepsilon_{t}
$$

where $\varepsilon_{t}^{\prime}=\left(\varepsilon_{x, t}, \varepsilon_{\pi, t}\right)$ is a shock to private expectations that is for simplicity assumed to be iid. The forecasts of the Central Bank are

$$
E_{t}^{C B} y_{t+1}=\tilde{E}_{t} y_{t+1}+\kappa \varepsilon_{t},
$$

where $\kappa=0$ or 1 , depending on whether the Central Bank is able to obtain precise information on the expectation shocks.

For the case of the expectations based rule (12) the modified reduced form is

$$
\begin{aligned}
& \left(\begin{array}{l}
x_{t} \\
\pi_{t}
\end{array}\right)=\left(\begin{array}{cc}
0 & -\frac{\lambda \beta}{\alpha+\lambda^{2}} \\
0 & \frac{\alpha \beta}{\alpha+\lambda^{2}}
\end{array}\right)\left(\begin{array}{c}
\tilde{E}_{t} x_{t+1} \\
\tilde{E}_{t} \pi_{t+1}
\end{array}\right)+ \\
& \left(\begin{array}{cc}
\frac{\alpha}{\alpha+\lambda^{2}} & 0 \\
\frac{\alpha \lambda}{\alpha+\lambda^{2}} & 0
\end{array}\right)\left(\begin{array}{l}
x_{t-1} \\
\pi_{t-1}
\end{array}\right)+\left(\begin{array}{cc}
0 & -\frac{\lambda}{\alpha+\lambda^{2}} \\
0 & \frac{\alpha}{\alpha+\lambda^{2}}
\end{array}\right)\left(\begin{array}{l}
g_{t} \\
u_{t}
\end{array}\right) \\
& +\left(\begin{array}{cc}
1-\kappa & \varphi(1-\kappa)-\frac{\kappa \lambda \beta}{\alpha+\lambda^{2}} \\
\lambda(1-\kappa) & \beta+\lambda \varphi(1-\kappa)-\frac{\kappa \lambda^{2} \beta}{\alpha+\lambda^{2}}
\end{array}\right)\left(\begin{array}{c}
\varepsilon_{x, t} \\
\varepsilon_{\pi, t}
\end{array}\right) .
\end{aligned}
$$

For the approximate targeting rule (24) the reduced form (25) changes to

$$
\begin{aligned}
\left(\begin{array}{c}
x_{t} \\
\pi_{t}
\end{array}\right)= & \left(\begin{array}{cc}
-\alpha \varphi \theta \lambda^{-1} & -\varphi \theta \\
-\alpha \varphi \theta & \beta-\varphi \theta \lambda
\end{array}\right)\left(\begin{array}{c}
\tilde{E}_{t} x_{t+1} \\
\tilde{E}_{t} \pi_{t+1}
\end{array}\right)+ \\
& \left(\begin{array}{cc}
\alpha \varphi \theta \lambda^{-1} & 0 \\
\alpha \varphi \theta & 0
\end{array}\right)\left(\begin{array}{c}
\tilde{E}_{t} x_{t} \\
\tilde{E}_{t} \pi_{t}
\end{array}\right)+\left(\begin{array}{cc}
1 & 0 \\
\lambda & 1
\end{array}\right)\left(\begin{array}{l}
g_{t} \\
u_{t}
\end{array}\right) \\
& +\left(\begin{array}{cc}
1 & \varphi \\
\lambda & \beta+\lambda \varphi
\end{array}\right)\left(\begin{array}{c}
\varepsilon_{x, t} \\
\varepsilon_{\pi, t}
\end{array}\right) .
\end{aligned}
$$


We note that E-stability and determinacy properties of the models are not affected by the expectation shocks.

From the reduced forms (26) and (27) we next calculate welfare losses due to unobserved expectations shocks. We assume that the standard deviation of the expectation shocks in output gap and inflation are 0.1 and 0.05 , respectively. The welfare losses for (12) and (24) with the different calibrations are

\begin{tabular}{|l||l|l|}
\hline Calibration & $W_{A T}$ & $W_{E B}$ \\
\hline \hline $\mathbf{W}$ & 7.231 & 1.524 \\
\hline $\mathbf{C G G}$ & 0.335 & 0.310 \\
\hline $\mathbf{M N}$ & 0.337 & 0.308 \\
\hline
\end{tabular}

Comparing these results to the preceding section it is seen that expectation shocks result in an increase in the losses under either rule. The computed losses suggest that the expectations based optimal rule seems to perform better than the forward looking approximate targeting rule.

However, the comparison could go the other way if there are big shocks to inflation expectations. We now increase the standard deviation for inflation expectation shocks first to 0.1 and then to 0.2 . In these cases the welfare losses are

\begin{tabular}{|l||l|l|}
\hline Calibration & $W_{A T}$ & $W_{E B}$ \\
\hline \hline W & 7.292 & 3.628 \\
\hline CGG & 0.339 & 0.331 \\
\hline MN & 0.339 & 0.321 \\
\hline
\end{tabular}

when the standard deviation for the inflation shock is 0.1 , and

\begin{tabular}{|l||l|l|}
\hline \multicolumn{1}{|l||}{ Calibration } & $W_{A T}$ & $W_{E B}$ \\
\hline \hline $\mathbf{W}$ & 7.537 & 12.044 \\
\hline $\mathbf{C G G}$ & 0.353 & 0.413 \\
\hline $\mathbf{M N}$ & 0.351 & 0.374 \\
\hline
\end{tabular}


when the standard deviation for the inflation shock is 0.2. It is seen that (24) delivers a smaller loss than (12) if the shocks to inflation expectations are sufficiently high.

Finally, we note that if the Central Bank has accurate information on the expectation shocks the welfare loss from the expectations based rule (12) is dramatically improved. We illustrate this for the last case in which the standard deviation of the output expectation shock is 0.1 and the standard deviation of the inflation expectation shock is 0.2 . Formally, setting $\kappa=1$ we obtain

\begin{tabular}{|l||l|}
\hline Calibration & $W_{E B}^{*}$ \\
\hline \hline $\mathbf{W}$ & 0.793 \\
\hline $\mathbf{C G G}$ & 0.319 \\
\hline $\mathbf{M N}$ & 0.319 \\
\hline
\end{tabular}

These welfare losses remain somewhat higher than the minimum losses without the expectation shocks, which were, respectively, 0.755, 0.296 and 0.296 for the three calibrations. Though the rule with $\kappa=1$ can neutralize fully the shocks to output gap expectations (see (26)), this is not the case for the shocks to inflation expectations. These results nonetheless illustrate the value of policy being able to condition on accurate observations of private expectations.

\section{Estimation of Structural Parameters}

Implementation of our expectations based optimal rule, as well as the approximate targeting rule, requires knowledge of structural parameters. A question of considerable interest is whether policy makers can obtain consistent estimates of $\lambda$ and $\varphi$ if private agents are learning. We take up this issue in the context of the expectations based rule. In (Evans and Honkapohja 2002a) we showed that consistent estimation of the structural parameters was possible in the case of optimal discretionary policy. Here we show how to carry out this procedure in the context of policy with commitment and we do so in a setting that requires instrumental variable estimation. 
First, we extend the model to allow for unobserved shocks. The IS and Phillips curves now take the form

$$
\begin{gathered}
x_{t}=-\varphi\left(i_{t}-E_{t}^{*} \pi_{t+1}\right)+E_{t}^{*} x_{t+1}+g_{t}+e_{x, t} \\
\pi_{t}=\lambda x_{t}+\beta E_{t}^{*} \pi_{t+1}+u_{t}+e_{\pi, t},
\end{gathered}
$$

where now $x_{t}, \pi_{t}, e_{x, t}$ and $e_{\pi, t}$ are not observable at time $t . g_{t}, u_{t}$ are observable at $t$ and $x_{t}, \pi_{t}$ are observed with a lag. It is assumed that the unobserved shocks $\left(e_{x, t}, e_{\pi, t}\right)$ are bivariate white noise but we will allow for the possibility that the components are contemporaneously correlated. $\left(g_{t}, u_{t}\right)$ and $\left(e_{x, t}, e_{\pi, t}\right)$ are exogenous and are assumed to be mutually independent. Private expectations are assumed to be observable and to be governed by least squares learning as above. We assume that $\beta$ and $\alpha$ are known, but the key structural parameters $\varphi$ and $\lambda$ must be estimated by the policy maker. The optimal REE now takes the form

$$
y_{t}=\bar{b} y_{t-1}+\bar{c} v_{t}+\bar{d} e_{t},
$$

where $e_{t}^{\prime}=\left(e_{x, t}, e_{\pi, t}\right)$.

Private agent learning is as before, with agents using least squares to estimate the parameters $a, b$ and $c$ of the PLM (17). Thus, at time $t$ agents use the PLM

$$
y_{t}=a_{t}+b_{t} y_{t-1}+c_{t} v_{t}+\eta_{t}
$$

to forecast $y_{t+1}$ using the forecast function (18) with $(a, b, c)$ replaced by $\left(a_{t}, b_{t}, c_{t}\right)$. To study the system under real time learning we express the least squares estimation in recursive form as follows. Define the matrix of parameters $\xi^{\prime}=(a, b, c)$ and the vector of state variables $z_{t}^{\prime}=\left(1, y_{t-1}^{\prime}, v_{t}^{\prime}\right)$. The recursive least squares algorithm is ${ }^{16}$

$$
\begin{aligned}
\xi_{t} & =\xi_{t-1}+t^{-1} R_{t-1}^{-1} z_{t-1}\left(y_{t-1}-\xi_{t-1}^{\prime} z_{t-1}\right)^{\prime} \\
R_{t} & =R_{t-1}+t^{-1}\left(z_{t-1} z_{t-1}^{\prime}-R_{t-1}\right)
\end{aligned}
$$

The $R_{t}$ equation updates estimates of the matrix of second moments of the regressors $z_{t}$. The parameters $\xi_{t}$ are updated using this matrix and the

\footnotetext{
${ }^{16}$ The recursive formulations for the parameter estimates vary slightly from least squares since we have introduced an additional lag in the equations for the second moments. This is analytically convenient. The same results apply if $R_{t-1}$ is replaced by $R_{t}$ in the first equation, see Chapter 10 of (Evans and Honkapohja 2001).
} 
regression errors $y_{t-1}-\xi_{t-1}^{\prime} z_{t-1}$. Note that $\xi_{t}$ is estimated using data through time $t-1$, which is the standard assumption in the literature.

To estimate the structural parameters the Central Bank constructs the variables

$$
\begin{aligned}
w_{x, t} & =x_{t}-E_{t}^{*} x_{t+1}-g_{t} \\
w_{\pi, t} & =\pi_{t}-\beta E_{t}^{*} \pi_{t+1}-u_{t} \\
r_{t} & =i_{t}-E_{t}^{*} \pi_{t+1} .
\end{aligned}
$$

Under the expectations based rule (12), in the REE $i_{t}$ depends on $g_{t}, u_{t}$, $x_{t-1}, E_{t}^{*} x_{t+1}$ and $E_{t}^{*} \pi_{t+1}$. Since $E_{t}^{*} x_{t+1}$ and $E_{t}^{*} \pi_{t+1}$ in turn depend on $g_{t}$, $u_{t}$, and $x_{t-1}$, it follows that $r_{t}$ depends only on $g_{t}, u_{t}$, and $x_{t-1}$. From (1) it also follows that $x_{t}$ depends only on $g_{t}, u_{t}, x_{t-1}$ and $e_{x, t}$. If $e_{x, t}$ and $e_{\pi, t}$ were known to be uncorrelated, consistent estimates of $\varphi$ and $\lambda$ could be obtained by least squares regressions of $w_{x, t}$ on $r_{t}$ and $w_{\pi, t}$ on $x_{t}$, respectively. Thus the policy maker would estimate

$$
\begin{aligned}
& w_{x, t}=-\varphi r_{t}+e_{x, t} \text { and } \\
& w_{\pi, t}=\lambda x_{t}+e_{\pi, t}
\end{aligned}
$$

using recursive least squares. However, we can allow for the possibility that the components $e_{x, t}$ and $e_{\pi, t}$ are contemporaneously correlated. We thus proceed as follows.

The first equation (30) can be estimated through least squares, since in the REE $r_{t}$ and $e_{x, t}$ are uncorrelated. ${ }^{17}$ Formally, we can write

$$
\begin{aligned}
\hat{\varphi}_{t} & =\hat{\varphi}_{t-1}+t^{-1} R_{r, t-1}^{-1} r_{t-1}\left(w_{x, t-1}-\left(-\hat{\varphi}_{t-1}\right) r_{t-1}\right) \\
R_{r, t} & =R_{r, t-1}+t^{-1}\left(r_{t-1}^{2}-R_{r, t-1}\right) .
\end{aligned}
$$

The second equation (31) must be estimated by recursive instrumental variables, since $x_{t}$ and $e_{\pi, t}$ are correlated in the REE. The natural instrument here is $x_{t-1}$. The recursive algorithm takes the form

$$
\begin{aligned}
& \hat{\lambda}_{t}^{I V}=\hat{\lambda}_{t-1}^{I V}+t^{-1}\left(R_{x, t-1}^{I V}\right)^{-1} x_{t-2}\left(w_{\pi, t-1}-\hat{\lambda}_{t-1}^{I V} x_{t-1}\right) \\
& R_{x, t}^{I V}=R_{x, t-1}^{I V}+t^{-1}\left(x_{t-2} x_{t-1}-R_{x, t-1}^{I V}\right) .
\end{aligned}
$$

\footnotetext{
${ }^{17}$ Note that this holds only if agents do not use contemporaneous values of $x_{t}$ and $\pi_{t}$ in forming expectations $E_{t}^{*} y_{t+1}$. If instead these contemporaneous values are used by private agents, then $\varphi$ as well as $\lambda$ would also have to be estimated using instrumental variables.
} 
The Central Bank is assumed to conduct monetary policy using the optimal expectations based rule (12) with estimated values for the structural parameters, i.e.

$$
i_{t}=\delta_{L, t} x_{t-1}+\delta_{\pi, t} E_{t}^{*} \pi_{t+1}+\delta_{x, t} E_{t}^{*} x_{t+1}+\delta_{g, t} g_{t}+\delta_{u, t} u_{t}
$$

where

$$
\begin{aligned}
\delta_{L, t} & =\frac{-\alpha}{\hat{\varphi}_{t}\left(\alpha+\left(\hat{\lambda}_{t}^{I V}\right)^{2}\right)}, \\
\delta_{\pi, t} & =1+\frac{\hat{\lambda}_{t}^{I V} \beta}{\hat{\varphi}_{t}\left(\alpha+\left(\hat{\lambda}_{t}^{I V}\right)^{2}\right)}, \delta_{x, t}=\hat{\varphi}_{t}^{-1}, \\
\delta_{g, t} & =\hat{\varphi}_{t}^{-1}, \delta_{u, t}=\frac{\hat{\lambda}_{t}^{I V}}{\hat{\varphi}_{t}\left(\alpha+\left(\hat{\lambda}_{t}^{I V}\right)^{2}\right)} .
\end{aligned}
$$

The key result is that the economy converges to the optimal REE when the Central Bank uses the optimal expectations based rule (34) and both private agents and policy maker learn using the specified algorithms. We remark that convergence to equilibrium is local in the sense that the initial parameter estimates can be chosen freely only within a neighborhood of the RE parameter values. Appendix 3 outlines the proof of this result.

As noted above, this result is robust to the assumption that agents use contemporaneous values of endogenous variables in the forecasts. In this case the equation (30) also must be estimated using recursive instrumental variables. Again $x_{t-1}$ can be used as the instrument.

\section{Conclusions}

The design of monetary policy needs to take into account the possibility that the economy may not always be in a full intertemporal, i.e. rational expectations, equilibrium. If economic agents update their forecasting procedures, the resulting process of learning may or may not lead the economy towards an REE. Convergence or non-convergence of the learning process depends critically on the policy rule followed by the Central Bank. We have reviewed recent research demonstrating that stability under learning is a serious concern. In particular, some recently proposed policy rules that depend solely 
on fundamentals are not conducive to convergence to equilibrium. We recommend instead expectations based optimal rules, i.e. interest rate rules depending appropriately on private expectations as well as fundamentals, which have been shown to lead to both stability under learning and determinacy of equilibria. We have also noted that, if non-optimal instrument rules are used instead, stability under learning imposes additional constraints on monetary policy rules, and policy design should take account of these constraints.

Implementation of interest rate rules raises several practical concerns. First, questions of observability can arise. These problems can relate to availability of current data and to forecasts of private agents. We have discussed ways for dealing with these concerns. Second, the economy may in practice be subject to expectation shocks, in addition to transitory shocks associated with learning. These will not usually alter the conditions for stability under learning, but if the shocks are sufficiently large the ranking of different policy rules can be affected. However, if private expectations are fully observable, this provides an additional motivation for following our recommended expectations based optimal rule.

Finally, implementation of expectations based or approximate targeting policy rules requires knowledge of key structural parameters. If the Central Bank does not have this knowledge, the problem can be overcome by appropriately estimating these parameters and using the estimated parameters in the interest rate rule. In particular, we have shown that this procedure is viable for the expectations based rule, which is locally stable under simultaneous learning by private agents and policy makers.

We hope that these rules provide useful guidelines for the design of monetary policy. However, we recognize that much further research on these issues remains to be done. 


\section{Appendix}

\section{Appendix 1: Derivation of Optimal REE and the Fundamentals Based $i_{t}$ rule}

Consider the model under rational expectations. It can be shown that the aggregate supply curve (2), the equation for $u_{t}$ given by (3), and the optimality condition (7) or (8) specify a unique nonexplosive solution. Consider the system under commitment, i.e. (8). The unique stationary solution takes the form

$$
\begin{aligned}
& x_{t}=b_{x} x_{t-1}+c_{x} u_{t}, \\
& \pi_{t}=b_{\pi} x_{t-1}+c_{\pi} u_{t},
\end{aligned}
$$

where $b_{x}$ is the solution $\left|b_{x}\right|<1$ to $\beta b_{x}^{2}-\left(1+\beta+\frac{\lambda^{2}}{\alpha}\right) b_{x}+1=0$ and where $b_{\pi}, c_{x}, c_{\pi}$ depend on the structural parameters. To obtain the fundamentals based $i_{t}$ rule, the corresponding rational expectations $E_{t} x_{t+1}$ and $E_{t} \pi_{t+1}$ are computed as linear functions of $x_{t-1}$ and $u_{t}$. Using the RE assumption, these expectation functions and the above expression for $x_{t}$ are substituted into the aggregate demand equation (1) and solved for $i_{t}$. This gives the fundamentals based rule (10), where

$$
\begin{aligned}
& \psi_{x}=b_{x}\left[\varphi^{-1}\left(b_{x}-1\right)+b_{\pi}\right], \quad \psi_{g}=\varphi^{-1}, \text { and } \\
& \psi_{u}=\left[b_{\pi}+\varphi^{-1}\left(b_{x}+\rho-1\right)\right] c_{x}+c_{\pi} \rho .
\end{aligned}
$$

Details are given in (Evans and Honkapohja 2002b). In the case of discretion similar steps lead to these coefficients with $\psi_{x}=b_{x}=b_{\pi}=0$. Details are given in (Evans and Honkapohja 2002a).

\section{Appendix 2: Welfare Calculation}

We calculate the expected welfare loss of the stationary REE, which is $1 /(1-\beta)$ times

$$
E\left(\alpha x_{t}^{2}+\pi_{t}^{2}\right)
$$

The REE solution $y_{t}=\bar{b} y_{t-1}+\bar{c} v_{t}$ can be written as

$$
\left(\begin{array}{c}
y_{t} \\
v_{t}
\end{array}\right)=\left(\begin{array}{cc}
\bar{b} & \bar{c} F \\
0 & F
\end{array}\right)\left(\begin{array}{c}
y_{t-1} \\
v_{t-1}
\end{array}\right)+\left(\begin{array}{c}
\bar{c} \\
I
\end{array}\right) \tilde{v}_{t}
$$


where $\tilde{v}_{t}=\left(\tilde{g}_{t}, \tilde{u}_{t}\right)^{\prime}$ and $\bar{b}$ and $\bar{c}$ are the REE values under the specified interest rate rule, or

$$
\zeta_{t}=G \zeta_{t-1}+H \tilde{v}_{t}
$$

where $\zeta_{t}^{\prime}=\left(y_{t}, v_{t}\right)$. Letting $\Sigma=\operatorname{Var}\left(\tilde{v}_{t}\right)$ denote the covariance matrix of the shocks $\tilde{v}_{t}$, the stationary covariance matrix for $\xi_{t}$ satisfies

$$
\operatorname{Var}\left(\zeta_{t}\right)=G \operatorname{Var}\left(\zeta_{t}\right) G^{\prime}+H \Sigma H^{\prime}
$$

or in vectorized form

$$
\operatorname{vec}\left(\operatorname{Var}\left(\zeta_{t}\right)\right)=[I-G \otimes G]^{-1} \operatorname{vec}\left(H \Sigma H^{\prime}\right)
$$

The variance of output gap and inflation can be read off from (37).

\section{Appendix 3: Convergence under Structural Estimation}

To demonstrate stability under the expectations based rule (34) when the private agents and the policy makers are simultaneously learning we apply the stochastic approximation tools described in Chapters 6 and 7 of (Evans and Honkapohja 2001). The key results in stochastic approximation state that conditions for local convergence of the recursive stochastic algorithms are given by the local asymptotic stability conditions for a system of associated differential equations. The steps required for deriving the associated differential equations for the stochastic recursive system are given in (Evans and Honkapohja 2001).

It can be shown that for the parameters of the private agents the associated differential equations are

$$
\begin{aligned}
\frac{d \xi}{d \tau} & =R_{z}^{-1} M_{z}(\vartheta) G\left(\xi, \hat{\varphi}, \hat{\lambda}^{I V} ; \varphi, \lambda\right), \\
\frac{d R_{z}}{d \tau} & =M_{z}(\vartheta)-R_{z} .
\end{aligned}
$$

Here $\vartheta_{t}$ denotes the vector of all parameters $a_{t}, b_{t}, c_{t}, \hat{\varphi}_{t}, \hat{\lambda}_{t}^{I V}$ and the second moment estimates. The function $G($.$) has the property$

$$
G(\xi, \varphi, \lambda ; \varphi, \lambda)=T(\xi)-\xi
$$


i.e. $G($.$) reduces to T(\xi)-\xi$ when the estimates $\hat{\varphi}, \hat{\lambda}^{I V}$ take their true values. Here $T(\xi)=T(a, b, c)$ is the mapping from the PLM to the ALM given by (19) with matrix coefficients (22).

The associated differential equations for the algorithms (32) and (33) are

$$
\begin{aligned}
\frac{d \hat{\varphi}}{d \tau} & =R_{r}^{-1} \operatorname{Er}_{t-1}(\vartheta)^{2}(\varphi-\hat{\varphi}) \\
\frac{d R_{r}}{d \tau} & =E r_{t-1}(\vartheta)^{2}-R_{r}
\end{aligned}
$$

since $\operatorname{Er}_{t-1}(\vartheta) e_{x, t-1}=0$, and

$$
\begin{aligned}
\frac{d \hat{\lambda}^{I V}}{d \tau} & =\left(R_{x}^{I V}\right)^{-1} E\left[x_{t-2}(\vartheta) x_{t-1}(\vartheta)\right]\left(\lambda-\hat{\lambda}^{I V}\right), \\
\frac{d R_{x}^{I V}}{d \tau} & =E\left[x_{t-2}(\vartheta) x_{t-1}(\vartheta)\right]-R_{x}^{I V},
\end{aligned}
$$

since $E x_{t-2}(\vartheta) e_{\pi, t-1}=0$. It should be noted that all the parameter estimates $\xi, \hat{\varphi}, \hat{\lambda}^{I V}, R_{z}, R_{r}$ and $R_{x}^{I V}$ in the differential equations are functions of $\tau$, which is a virtual time concept.

To study convergence under real time learning, one considers local asymptotic stability of the entire differential equation system at the REE $\vartheta^{*}$. To analyze stability of the system we first note that differential equations for all of the second moments are stable. It then follows that $\hat{\varphi} \rightarrow \varphi$ and $\hat{\lambda}^{I V} \rightarrow \lambda$. Using (38) it follows that stability of the system reduces to the earlier E-stability differential equation (20) for the model with commitment. Thus we have the local stability results that the policy maker learns the structural parameters, private agents learn RE and the economy converges the optimal REE. ${ }^{18}$

\footnotetext{
${ }^{18}$ Details of the stochastic approximation convergence argument are given for the discretionary policy case in (Evans and Honkapohja 2002a).
} 


\section{References}

BAnk Of England, U. K. (2002): Inflation Report. Bank of England, www.bankofengland.co.uk/inflationreport/index.htm.

Bernanke, B., And M. Woodford (1997): "Inflation Forecasts and Monetary Policy," Journal of Money, Credit, and Banking, 24, 653-684.

Blinder, A. S. (1998): Central Banking in Theory and Practice. MIT Press, Cambridge, Mass.

Bullard, J., AND K. Mitra (2001): "Determinacy, Learnability and Monetary Policy Inertia," Working paper, www.stls.frb.org/research/econ/bullard.

- (2002): "Learning About Monetary Policy Rules," Journal of Monetary Economics, 49, 1105-1129.

Calvo, G. A. (1983): "Staggered Pricing in a Utility-Maximizing Framework," Journal of Monetary Economics, 12, 383-398.

Carlstrom, C. T., and T. S. Fuerst (2001): "Learning and the Central Bank," mimeo, Bowling Green State University.

Clarida, R., J. Gali, and M. Gertler (1998): "Monetary Policy Rules in Practice: Some International Evidence," European Economic Review, 42, 1033-1067.

spective," Journal of Economic Literature, 37, 1661-1707.

(2000): "Monetary Policy Rules and Macroeconomic Stability: Evidence and Some Theory," Quarterly Journal of Economics, 115, 147-180.

European Central Bank, E. U. (2002): Monthly Bulletin. European Central Bank, www.ecb.int.

Evans, G. W. (2001): "Expectations in Economics: Adaptive versus Eductive Learning," Revue Economique, 52, 573-582. 
Evans, G. W., and S. Honkapohja (1995): "Adaptive Learning and Expectational Stability: An Introduction," in (Kirman and Salmon 1995), chap. 4, pp. 102-126.

- (1999): "Learning Dynamics," in (Taylor and Woodford 1999), chap. 7, pp. 449-542.

(2001): Learning and Expectations in Macroeconomics. Princeton University Press, Princeton, New Jersey.

(2002a): "Expectations and the Stability Problem for Optimal Monetary Policies," Review of Economic Studies, forthcoming.

- (2002b): "Monetary Policy, Expectations and Commitment," mimeo, www.valt.helsinki.fi/RAKA/seppo.hmtl, and http://darkwing.uoregon.edu/ gevans/.

- (2002c): "Policy Interaction, Learning and the Fiscal Theory of Prices," mimeo, www.valt.helsinki.fi/RAKA/seppo.hmtl, and http://darkwing.uoregon.edu/ gevans/.

Evans, G. W., And G. Ramey (2001): "Adaptive Expectations, Underparameterization and the Lucas Critique," Working paper 237, University of Oregon.

Federal Reserve Bank, K. C. (1984): Price Stability and Public Policy. Federal Reserve Bank of Kansas City, Kansas City.

_ (1999): New Challenges for Monetary Policy. Federal Reserve Bank of Kansas City, Kansas City.

Ferrero, G. (2002): "Learning and Monetary Policy," mimeo.

Guesnerie, R. (2002): "Anchoring Economic Predictions in Common Knowledge," Econometrica, 70, 439-480.

Hall, R. E. (1984): "Monetary Strategy with an Elastic Price Standard," in (Federal Reserve Bank 1984), chap. 6, pp. 137-159.

Honkapohja, S., And K. Mitra (2001a): "Are Non-Fundamental Equilibria Learnable in Models of Monetary Policy?," Working paper, www.valt.helsinki.fi/RAKA/seppo.hmtl. 
(2001b): "Learning Stability in Economies with Heterogenous Agents," manuscript, www.valt.helsinki.fi/RAKA/seppo.hmtl.

(2002): "Performance of Monetary Policy with Internal Central Bank Forecasting," manuscript, www.valt.helsinki.fi/RAKA/seppo.hmtl.

Honkapohja, S., K. Mitra, and G. W. Evans (2002): "Notes on Agents' Behavioral Rules Under Adaptive Learning and Recent Studies of Monetary Policy," manuscript, www.valt.helsinki.fi/RAKA/seppo.hmtl, and http://darkwing.uoregon.edu/ gevans.

HowitT, P. (1992): "Interest Rate Control and Nonconvergence to Rational Expectations," Journal of Political Economy, 100, 776-800.

Kirman, A., and M. Salmon (eds.) (1995): Learning and Rationality in Economics. Basil Blackwell, Oxford.

Kreps, D., And K. Wallis (eds.) (1997): Advances in Economics and Econometrics: Theory and Applications, Volume I. Cambridge University Press, Cambridge.

Marimon, R. (1997): "Learning from Learning in Economics," in (Kreps and Wallis 1997), chap. 9, pp. 278-315.

McCallum, B. T. (1999): "Issues in the Design of Monetary Policy Rules," in (Taylor and Woodford 1999), chap. 23, pp. 1483-1530.

(2002): "The Fiscal Theory of the Price Level is not Learnable," mimeo, Carnegie Mellon University.

McCallum, B. T., and E. Nelson (1999): "Performance of Operational Policy Rules in an Estimated Semi-Classical Model," in (Taylor 1999), pp. 15-45.

(2000): "Timeless Perspective vs. Discretionary Monetary Policy in Forward-Looking Models," mimeo, Carnegie Mellon University and Bank of England.

Mitra, K. (2001): "Desirability of Nominal GDP Targeting Under Adaptive Learning," Journal of Money, Credit, and Banking, forthcoming. 
Orphanides, A., and J. C. Williams (2002): "Imperfect Knowledge, Inflation Expectations, and Monetary Policy," Working paper 02-04, Federal Reserve Bank of San Francisco.

Preston, B. (2002): "Learning about Monetary Policy Rules when LongHorizon Forecasts Matter," mimeo, Princeton University.

Sargent, T. J. (1993): Bounded Rationality in Macroeconomics. Oxford University Press, Oxford.

(1999): The Conquest of American Inflation. Princeton University Press, Princeton NJ.

Svensson, L. E. (1999): "Inflation Targeting as a Monetary Policy Rule," Journal of Monetary Economics, 43, 607-654.

Svensson, L. E. (2001): "What Is Wrong with Taylor Rules? Using Judgment in Monetary Policy through Targeting Rules," mimeo.

Svensson, L. E. O., and M. Woodford (1999): "Implementing Optimal Policy through Inflation-Forecast Targeting," Working paper.

TAYlor, J. (1993): "Discretion versus Policy Rules in Practice," CarnegieRochester Conference Series in Public Policy, 39, 195-214.

(ed.) (1999): Monetary Policy Rules. University of Chicago Press, Chicago.

Taylor, J., And M. Woodford (eds.) (1999): Handbook of Macroeconomics, Volume 1. Elsevier, Amsterdam.

Woodford, M. (1996): "Control of the Public Debt: A Requirement for Price Stability?," Working paper, NBER WP5684.

(1999a): "Commentary: How Should Monetary Policy Be Conducted in an Era of Price Stability?," in (Federal Reserve Bank 1999), pp. $277-316$.

- (1999b): "Optimal Monetary Policy Inertia," The Manchester School, Supplement, 67, 1-35. 